\title{
A model of river bank deformations under the simultaneous effect of waves from a hydropower plant and warming
}

\author{
ELENA DEBOLSKAYA
}

Institute for Water Problems of the Russian Academy of Science, Gubkina str., 3, Moscow, Russia, 119333

e debolskaya@yahoo.com

\begin{abstract}
This paper presents a mathematical model of the river bed deformations in permafrost areas. The deformations are caused by the influence of waves of various origins under an increase of the ambient temperature. The model system consists of an unsteady hydrodynamic module, a thermal module and a bed deformation module. The hydrodynamic module is based on the two-dimensional shallow water equations. The bed deformation module is based on the sediment mass balance conditions. The thermal module is based on the Stefan equation, which defines the "water-ice" boundary movement. We present two applications of the model in which the bed deformation is calculated for the alluvial channels with melting bed under the influences of waves of different duration and intensity. We compared the model predictions with the laboratory data, generally obtaining a good agreement between the two.
\end{abstract}

Key words bed deformations; melting; waves; mathematical modelling

\section{INTRODUCTION}

Arctic regions are very sensitive to global climate change and hydrological systems in these regions are sensitive to the rising temperature. Banks of the rivers and reservoirs located in the permafrost zone are to a considerable extent composed of the frozen soil and the underground ice. This structure of the banks makes the abrasion processes even more pronounced (Dallimore, et al. 1996, Coastard et al. 2007, Bowden 2010). The laboratory experiments and field observations (Randriamazaoro et al. 2007, Dupeyrat et al. 2011) showed that thermoerosion plays a significant role in the deformation of the banks composed of permafrost with the inclusion of layers of ice. Sometimes the effect of thermoerosion is greater than that of mechanical erosion. Descriptions of the bed deformations caused by the interaction of mechanical and thermal erosion can be traced in the literature back to 1932. In 1957, R. V. Abramov (1957) introduced the term "thermo-erosional niching". Since the 1970s the interest in studying the impact of permafrost on channel processes increased in connection with the development of hydrocarbon deposits. We modelled the formation of thermo-erosional niches and the simultaneous effects of the thermal and mechanical erosion in the laboratory experiments using the following set-up. Two ice plates of equal thickness were embedded in a bank slope at different depths. Under the influence of the flowing water the ice plates melted and formed a cavity in which small streams occurred. With the loss of support of the ice plates the layers of soil began to settle due to gravity. Furthermore, the flow in the cavity causes a deformation of the walls. Our model describes the process of the lateral bed deformations, and in particular the niching process and allows answering some long standing questions, for instance, what is the role of the icing process in the soil erodibility. Figure 1 shows the crosssection of the model (plane $\mathrm{y}-\mathrm{z}$ ) corresponding to the laboratory experiments (a) and the photo of the tray (b). Main flow is along the $\mathrm{x}$ axis. The length of the study region is $1.5 \mathrm{~m}$; the right bank is vertical and the left bank has a slope. The width of the flow is $0.5 \mathrm{~m}$ at the water surface and $0.3 \mathrm{~m}$ at the bottom. The depth is $0.1 \mathrm{~m}$. Thickness of each of the two ice plates placed in the left bank is $0.02 \mathrm{~m}$. Water discharge is constant and equal to $3.9 \mathrm{~L} / \mathrm{s}$. The water temperature increased from $7^{\circ} \mathrm{C}$ to $17^{\circ} \mathrm{C}$ in $4 \mathrm{~h}$.

\section{Mathematical model}

The model system consists of a thermal module, an hydrodynamic module and a bed deformation module. We made several assumptions: the main thermal impact on ice plates occurs from a heating-up water stream on the surface of their direct contact; the problem of heat exchange in the soil was not considered; the "water-ice" interface moves uniformly along the axis $x$ and $z$. Then to 


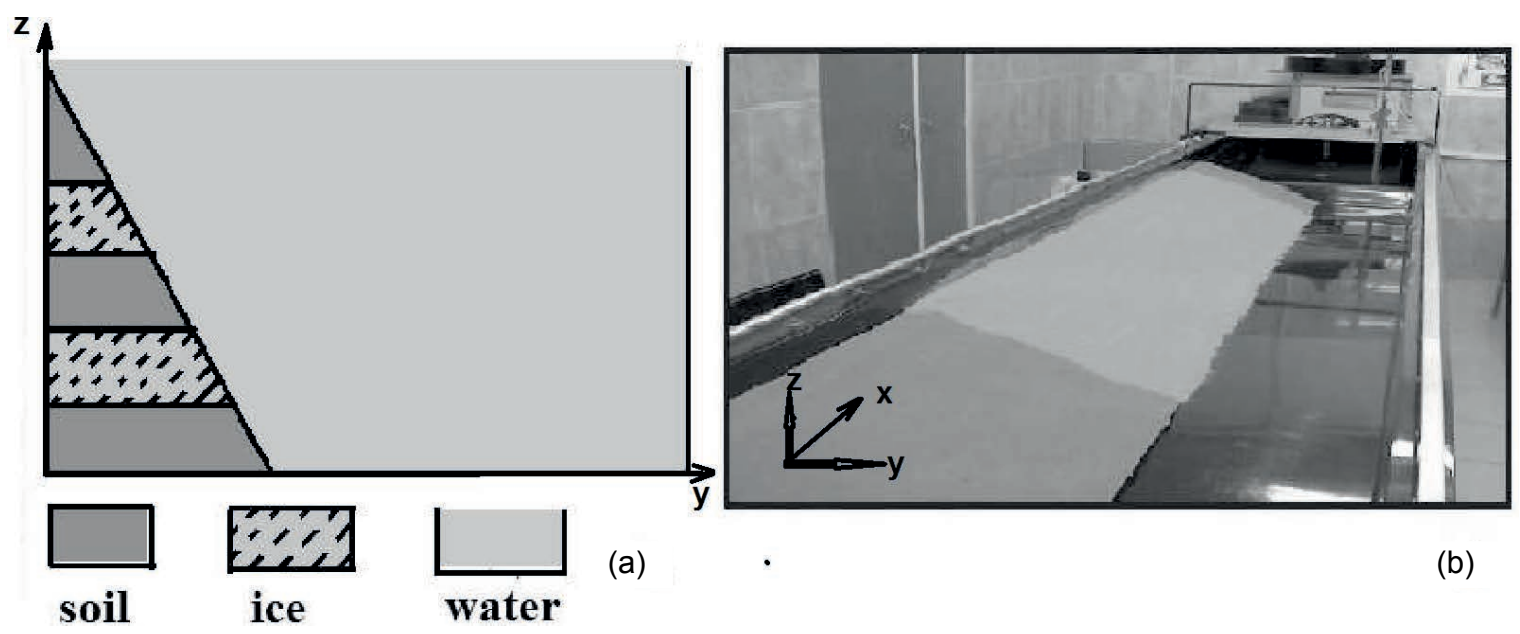

Fig. 1 A cross section (plane $y-z$ ) corresponding to the laboratory experiments (a) and the photo of the tray (b).

calculate the movement of the phase transition surface we can use a one-dimensional (1-D) equation in the form of the Stefan condition:

$$
\frac{\partial T}{\partial y}=\alpha \frac{\partial \xi}{\partial t}
$$

where, $\alpha=L \rho /\left(\lambda_{1}-\lambda_{2}\right), \lambda_{1}, \lambda_{2}$ are thermal conductivities of ice and the water, $L$ is latent heat of a melting of ice, $\rho$ is ice density, $\xi$ is the coordinate of the phase boundary or size by which the cross section of the ice plate decreases in the process of melting, $T$ is temperature, $t$ is time, $y$ is the transversal coordinate along which these plates are melting. On the boundary of the phase transition the temperature was set to zero.

The hydrodynamic block of the model consists of the 2-D nonstationary shallow water equations and the continuity equation:

$$
\begin{aligned}
& \frac{\partial u}{\partial t}+u \frac{\partial u}{\partial x}+v \frac{\partial u}{\partial y}=-g \frac{\partial H}{\partial x}+\frac{\partial}{\partial x}\left(A_{x} \frac{\partial u}{\partial x}\right)+\frac{\partial}{\partial y}\left(A_{y} \frac{\partial u}{\partial y}\right)+\frac{\tau_{b x}}{\rho_{\mathrm{w}} h} \\
& \frac{\partial v}{\partial t}+u \frac{\partial v}{\partial x}+v \frac{\partial v}{\partial y}=-g \frac{\partial H}{\partial y}+\frac{\partial}{\partial x}\left(A_{x} \frac{\partial v}{\partial x}\right)+\frac{\partial}{\partial y}\left(A_{y} \frac{\partial v}{\partial y}\right)+\frac{\tau_{b y}}{\rho_{\mathrm{w}} h} \\
& \frac{\partial H}{\partial t}+\frac{\partial H u}{\partial x}+\frac{\partial H v}{\partial y}=0
\end{aligned}
$$

where $\rho_{\mathrm{w}}$ is water density, $x, y$ are Cartesian axis; the positive axis $x$ is directed along the stream, the axis $y$ is across; $u, v$ are the longitudinal and transversal components of the water velocity averaged along the stream depth, respectively; $g$ is acceleration due to gravity; $H=h+h_{0}$ is the level or the water surface mark; $h_{0}$ is a mark of the bottom; $h$ is stream depth; and $\tau_{b x}$ and $\tau_{b y}$ are the components of the tangential stress at the bottom; $A_{x}$ and $A_{y}$ are longitudinal and transversal coefficients of turbulent viscosity, respectively. Coefficients of the turbulent viscosity were determined from the empirical relations $A_{x}=\gamma_{x} h u, A_{y}=\gamma_{y} h v$, whereby $\gamma_{x}, \gamma_{y}$ are empirical constants. The relationship between the shear stresses on hard surfaces and other characteristics of the flow is given by $\tau_{b i}=\frac{\rho \lambda U_{i}|\vec{U}|}{2}$, where the hydraulic friction coefficient is determined from the Mannings formula $\lambda=\frac{2 g n^{2}}{h^{1 / 3}}, n$ is roughness, $\vec{U}$ is the velocity vector in the plane, $U_{1}=u, U_{2}=v$, the indexes $i=1,2$ correspond to the $x$ and $y$ coordinates.

The melting bank deformation is determined by the soil subsidence under gravity and erosion caused by the water flow. It is possible to parametize the process of the subsidence of the soil lying over the cavity formed after melting of the ice plate by a ratio, which is similar to the dependency 
describing the loss of stability of the joist that is clamped at one end and lies on an elastic foundation:

$$
\delta=\beta y_{*}{ }^{2} / h_{*}
$$

where $y_{*}$ is the transverse dimension of the melted patch, $h_{*}$ is thickness of the soil layer above the cavity (see Fig. 1(a)), $\beta$ is a parameter characterizing the cohesion of soil. Deformation of the bed in the main channel and the solid boundaries in melting patch cavities due to the impact of the water flow was calculated from the equation of mass balance for sediment:

$$
\frac{\partial}{\partial t}\left((1-p) h_{0}\right)+\frac{\partial Q_{s x}}{\partial x}+\frac{\partial Q_{s y}}{\partial y}=0
$$

where $p$ is porosity of the bottom material, $Q_{s x}, Q_{s y}$ are longitudinal and transverse components of the sediment discharge per unit width. For their definition Engelund's dependence was used (Debolskaya et al. 2006).

The algorithm is constructed in such a way that equations for the open part of the flow and for the melted patch cavities (niches) are solved in the separate systems of equations for both the velocity and bed deformation. The condition of equality of the solid discharge at the boundaries between the niches and the main stream is assumed.

\section{Validation of the model and results}

Validation of the model was carried out for the case of the steady-state flow in a tray.

Figure 2(a) shows the topography of the bank slope at 60 minutes after the start of the numerical experiment and Fig. 2(b) shows a picture of the slope after a laboratory experiment with the same parameters as in the numerical experiment. In the laboratory experiments the slope angle changed from $26^{\circ}$ at the beginning to $22^{\circ}$ after 60 minutes. In the computer simulations this angle changed from of $26^{\circ}$ to $20.5^{\circ}-22^{\circ}$ depending on the variations of the parameter characterising the cohesion of soil. Thus, the dynamic picture of the slope rearrangement (the formation of the steep ledges in the melting areas and the subsequent flattening out at the expense of the soil slippage) corresponded to the description of the process in the laboratory experiment and natural observations. The observations of coastal erosion of the Lena River and measurement of the water temperature allowed establishing a direct dependency for the increase of the volume of the deformations caused by thermoerosion on the increasing temperature of the water during the flood (Coastard et al. 2007, Dupeyrat et al. 2011). Simulation of this dependency in the work of Randriamazaoro et al. (2007) showed that the erosion rate can increase by an average of $20 \%$ with an increase of the water temperature by $2^{\circ} \mathrm{C}$. These results were used to test the model presented

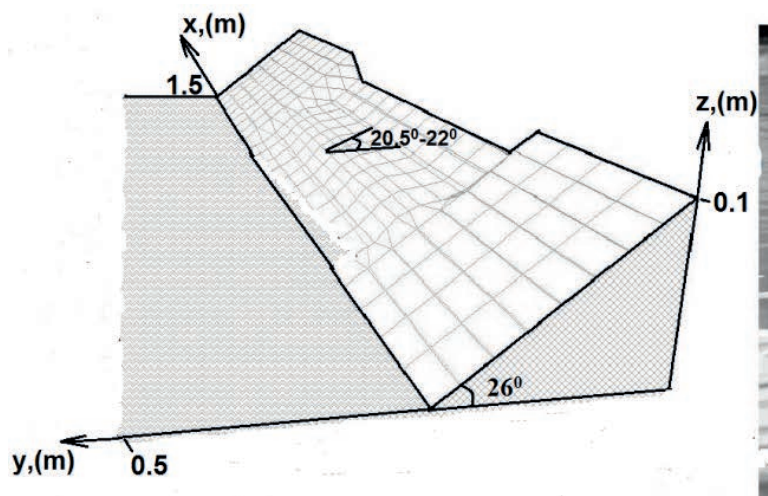

(a)

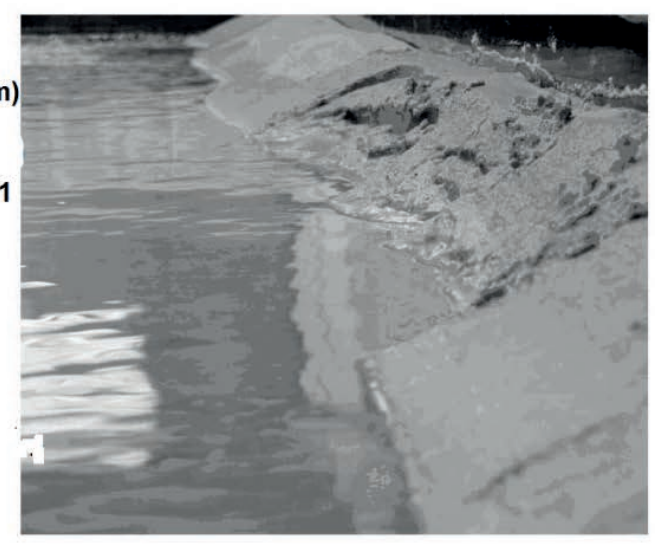

(b)

Fig. 2 The topography of the bank at 60 minutes of the simulation time after the start of the numerical experiment (a), a picture of a slope after a laboratory experiment with the same parameters (b). 
here. Calculation of the increase in volume of the deformations caused by the $2{ }^{\circ} \mathrm{C}$ increase in the water temperature, gives an estimate of the process acceleration by $25 \%$ in average. This confirms the conclusions obtained from the natural observations and other simulation approaches.

Dupeyrat et al. (2008) assessed the thermal boundary layer and the rate of erosion for the flow along the bottom on the basis of mathematical modelling using a 1-D heat equation and empirical relationships for transfer coefficient. These estimations have been compared with the laboratory data obtained in the tray with sand bottom and different content of ice. According to the mathematical modelling by Dupeyrat et al. (2008) the rate of erosion varied depending upon the ice content from $0.6 \mathrm{~mm} / \mathrm{min}$ (for pure ice ) to $1.6 \mathrm{~mm} / \mathrm{min}$ (at $20 \%$ ice content) for the flow with a Reynolds number $R e=15900$ when the water temperature was $5.5^{\circ} \mathrm{C}$. According to laboratory experiments by Dupeyrat et al. (2008) these values changed from $0.7 \mathrm{~mm} / \mathrm{min}$ to $2.2 \mathrm{~mm} / \mathrm{min}$, respectively. According to our mathematical model the magnitude of the erosion rate was $1 \mathrm{~mm} / \mathrm{min}$ when the water temperature was $9^{\circ} \mathrm{C}$ and $0.7 \mathrm{~mm} / \mathrm{min}$ at $7^{\circ} \mathrm{C}$. Reynolds number $\mathrm{Re}$ was 14000 . According to our laboratory experiment the erosion rate was evaluated in the range of $0.25 \mathrm{~mm} / \mathrm{min}$ up to $1 \mathrm{~mm} / \mathrm{min}$ depending on the temperature of the surrounding soil. Before the experiments soil was cooled to $4^{\circ} \mathrm{C}$. Figure 3 shows variation of the erosion and the temperature of the ambient soil in time according to laboratory experiment (Fig. 3(a)), the rate of erosion from the soil temperature (Fig. 3(b)) according to laboratory and numerical experiments.

(a)

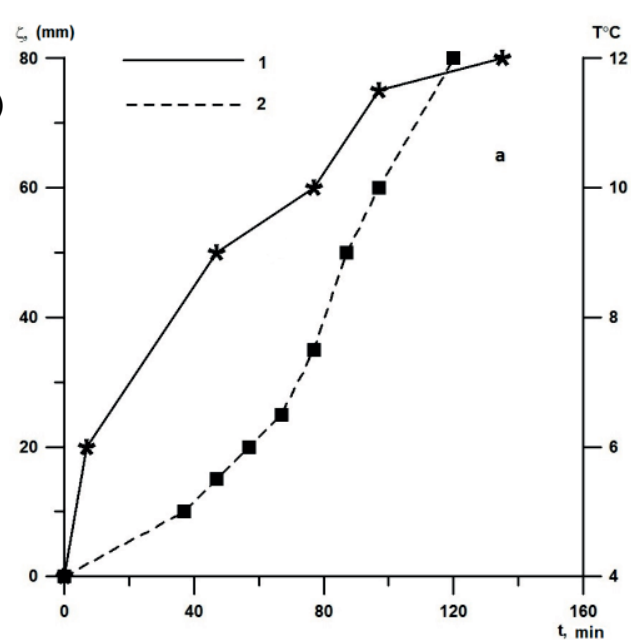

(b)

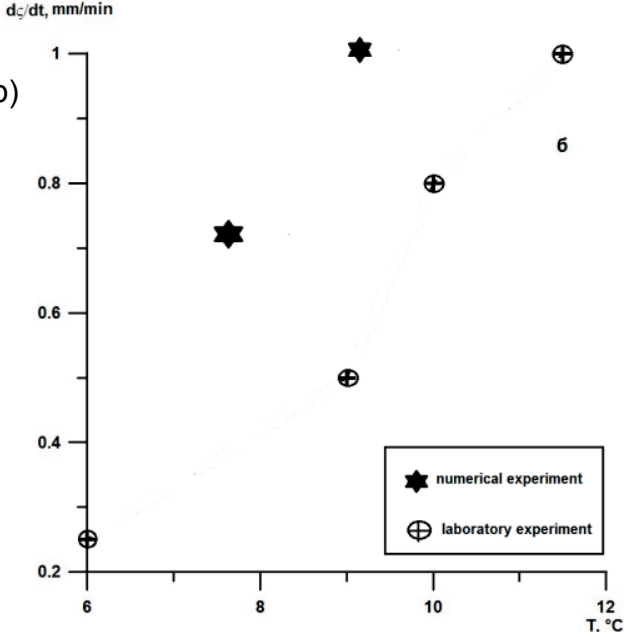

Fig. 3 The dependencies of temperature (1) and erosion (2) of the ambient soil from time according to laboratory experiment (a), the rate of erosion from the soil temperature according to laboratory and numerical experiments (b).

To investigate the deformations of the bed caused by the waves of different duration and amplitude, numerical experiments were carried out with the wave acting in the form of releases with an amplitude exceeding the initial depth of the flow by 1.7 times and duration of 2 seconds. If we compare the influence of the same wave for two cases: in the presence of ice plates in a coastal slope and in their absence, it is possible to see that the total deviation of the marks of the underlying surface from the initial position in the presence of ice plates is less than in their absence, i.e. erosion and sediment accumulation are more balanced in the whole of the area, including the bottom and the banks, in contrast to the predominance of siltation without ice inclusions. However, the amplitudes of the positive and negative deviations are much larger, than in the soils without ice inclusions, i.e. erosion and accumulation are stronger not only in the area where the ice plates are located but also downstream (Fig. 4).

We carried out some numerical experiments to determine the dependency of the bed deformations on the amplitude and period of the wave and on the compendency of the soil. The relation of the depth of the flow at an entrance section to the initial depth of the undisturbed flow $(\mathrm{Krel})$ is the parameter characterizing the amplitude of the wave perturbation. 


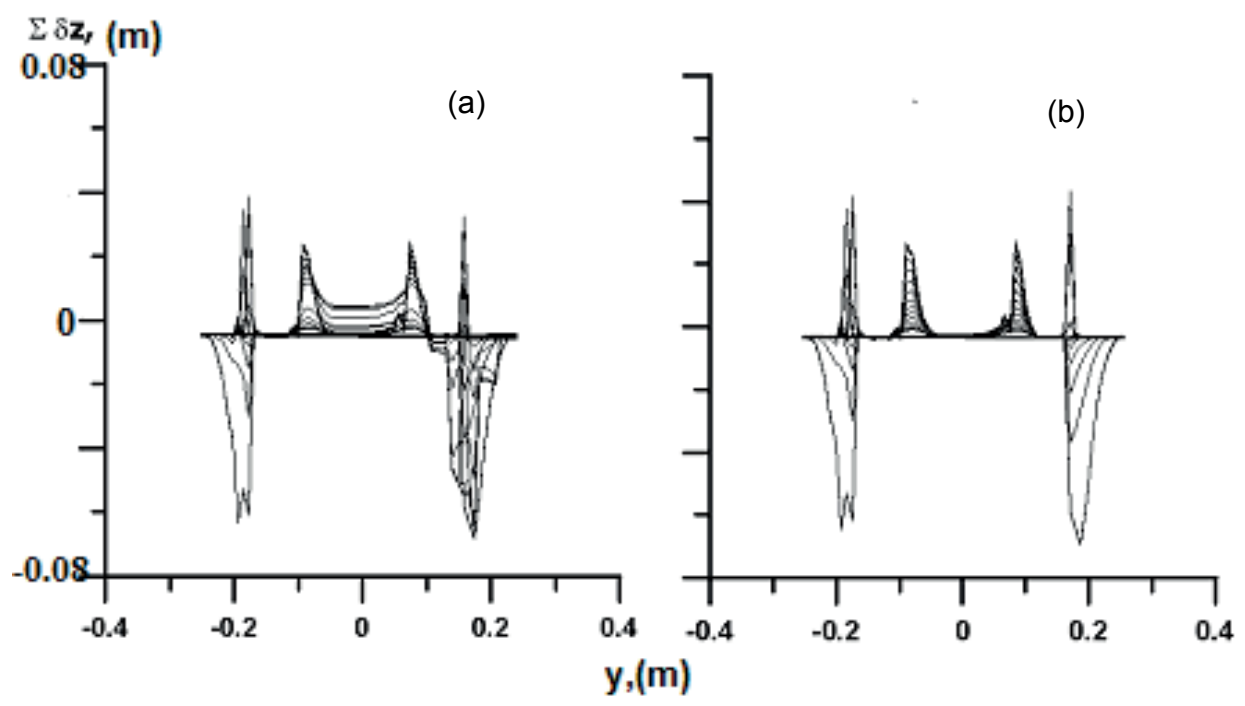

Fig. 4 The positions of the bottom surfaces summed for all sections and time for the case of the presence of ice plates (a) in coastal slope and without them (b).

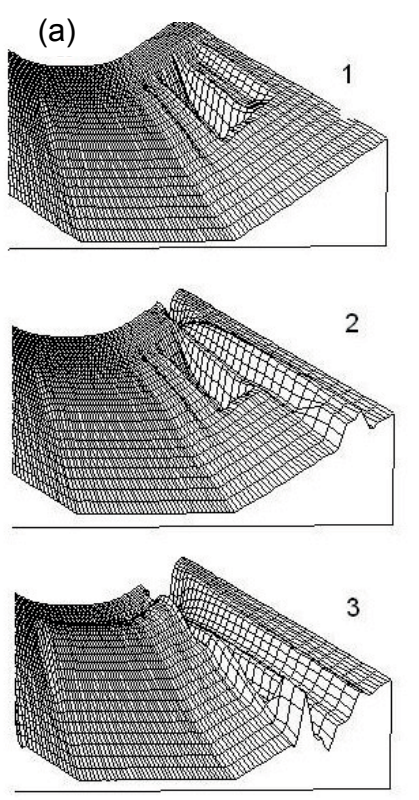

(b)

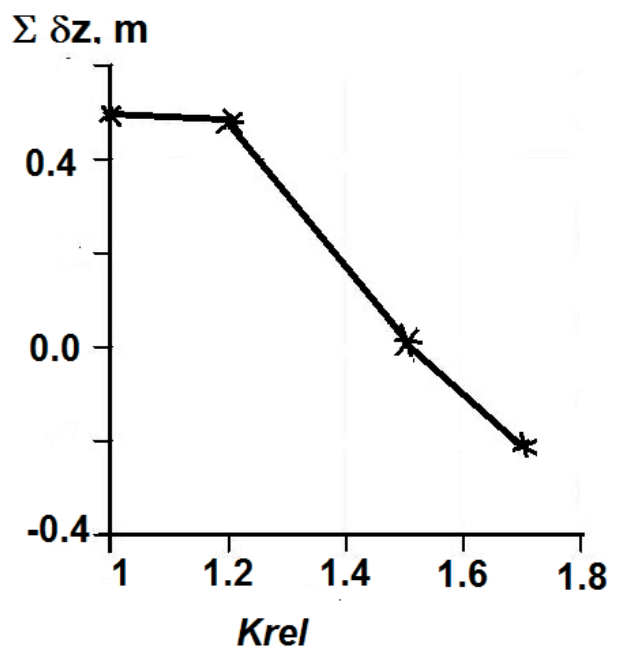

Fig. 5 The topography of the coastal slope formed after 40 minutes of the simulated time after the start of the experiment ((1) at Krel $=1$; (2) at $\mathrm{Krel}=1.2$; (3) Krel = 1.5) (a), the dependence of sum of deviations of the bed surface from parameters of releases Krel.

(a)
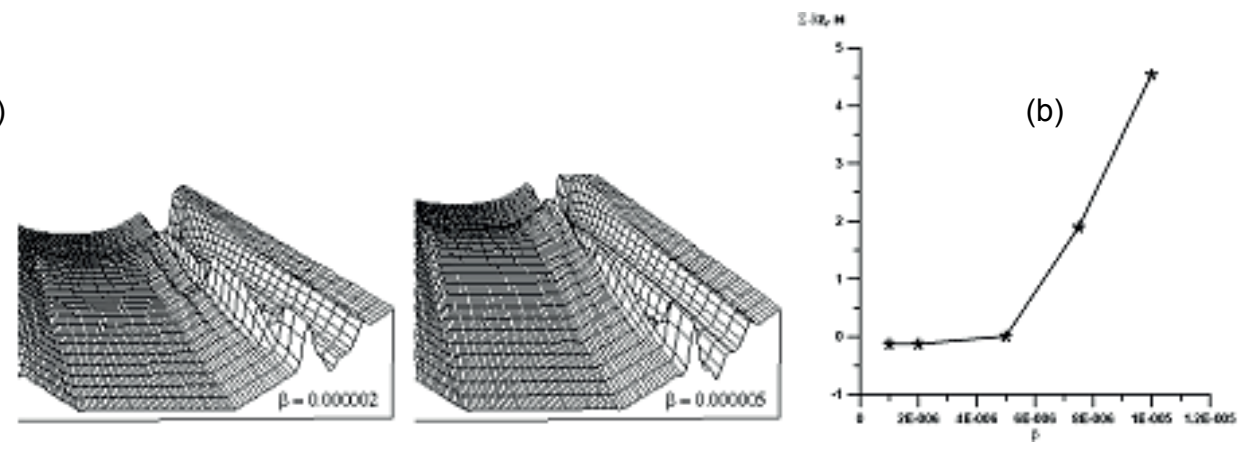

Fig. 6 The topography of the coastal slope formed after 40 minutes of the simulated time after the start of the experiment at different soil cohesion coefficients (Krel=1.5) (a), the dependence of sum of deviations of the bed surface from the soil cohesion coefficient (b). 
Figure 5(a) shows the topography of the coastal slope formed after 40 minutes of simulated time after the start of the experiment, in the case of the steady flow (without releases) and in streams with parameters of releases $\mathrm{Krel}=1.2$ and 1.5. Water temperature during this period increased from $7^{\circ} \mathrm{C}$ to $8.7^{\circ} \mathrm{C}$. Figure $5(\mathrm{~b})$ shows the dependency of the sum of deviations of the bed surface from initial state for the same cases. Increasing amplitude of the wave changes the trend from the total silting to the total washout. The numerical experiments to determine the effect of soil cohesion on the bed deformation were carried out also. The variable parameter $\beta$ is the coefficient in equation (5). Figure 6 shows the results of numerical experiments.

\section{CONCLUSIONS}

The heating of a water stream with layers of the ice in a coastal slope render an integro-differential multidirectional effect on the riverbed deformations caused by wave influence. This effect consists in strengthening of processes of erosion and accumulation on a separate site at a simultaneous decrease of the total volume of the transported sediments.

The increase of a wave amplitude causes transition from a total accumulation to a total erosion.

Experiments with other parameters showed that, with the increasing duration of the wave, there is a tendency for sediment accumulation.

Increased soil cohesion parameter led to a transition from the erosion (the negative sums of deviations of a bottom surface) to the accumulation of sediment.

\section{REFERENCES}

Abramov, R. V. (1957) Nishi vytaivaniya (Thaw-out niches). Priroda 46(7), 112-113.

Bowden, W. B. (2010) Climate change in the Arctic-Permafrost, thermokarst, and why they matter to the non Arctic World. Geography Compass, v. 4, no. 10, 1553-1566, doi: 10.1111/j.1749-8198.2010.00390.x

Coastard F. et al. (2007) Impact of the global warming on the fluvial thermal erosion over the Lena River in Central Siberia. Geophysical Research letters, 34, L14501, doi:10.1029/2007GL030212.

Dallimore, S. R., Wolfe, S. A., and Solomon, S. M. (1996), Influence of ground ice and permafrost on coastal evolution, Richards Island, Beaufort Sea coast, NWT: Canadian Journal of Earth Sciences 33(5), 664-675.

Debolskaya, E. I., Debolskii, V. K. and Maslikova, O. Ya. (2006) Mathematical modeling of bed deformations in ice-covered non-steady-state flow. In: Proc 18th IAHR International Symposium on Ice, Japan, 53-60.

Dupeyrat, L., et al. (2011) Effects of ice content on the thermal erosion of permafrost: implications for coastal and fluvial erosion. Permafrost and Periglacial Processes 22, 179-187.

Dupeyrat L., et al. (2008) Variable rate modeling of fluvial thermal erosion. In: Proc. Ninth International Conference on Permafrost (ed. by D. L. Kane and K. M. Hinkel). V. 1, 391-395.

Randriamazaoro, R. et al. (2007) Fluvial thermal erosion: heat balance integral method. Earth Surface Processes and Landforms 32(12), 1828-1840. 